\title{
DA INSTRANSPONIBILIDADE ENTRE DESCRIÇÃO E PRESCRIÇÃO: UM ENSAIO SOBRE PRAGMATISMO E DIREITO
}

\author{
THE INTRANSPONIBILITY BETWEEN DESCRIPTION AND \\ PRESCRIPTION: AN ESSAY ON PRAGMATISM AND LAW
}

\author{
Lorena Freitas* \\ Enoque Feitosa**
}

Recebido: 11/2017

Aprovado: 11/2017

\begin{abstract}
Resumo: A estrutura deste trabalho baseia-se no quadro teórico de David Hume. A sua construção formal é a de um ensaio e o problema da pesquisa é investigar se a falácia naturalista da Hume também pode ser usada para criticar as inferências legais. Considerando o problema humeano "ser-dever ser", nossa hipótese é que o pensamento tradicional jurídico deduz um "dever" de um "é" - e não é óbvio como um pode passar de forma coerente de declarações descritivas para prescritivas. Este artigo promove um diálogo entre o pensamento humeano e o realismo jurídico a partir de um ponto de vista cético.
\end{abstract}

Palavras-chave: David Hume. Realismo Jurídico. Prescrição. Descrição.

\begin{abstract}
The structure of this work is based on David Hume's framework. The formal structure is an essay and the problem of research is to investigate if the Hume's naturalistic fallacy is may also be used to criticize the legal inferences. Considering the "is-ought" humean problem, our hipothesis is that legal traditional thought causes the deduction of an "ought" from an "is" - and it is not obvious how one can coherently move from descriptive statements to prescriptive ones. This paper promoves a dialogue between humean and legal realism from the sceptical point of view.
\end{abstract}

Key-words: David Hume. Legal Realism. Prescription. Description.

\section{Preliminares: o ensaio e sua unidade humeana}

Este artigo se propõe como um ensaio ${ }^{1}$ ao perseguir as características da liberdade e de variedade às quais Hume recorre sem dispensar a unidade. A síntese da proposta ensaística perpassaria a "perspicuidade de estilo" de que fala Adam Smith nas primeiras linhas da $2^{a}$ Conferência Sobre Retórica e Belasletras $^{2}$, mas centralmente tal liberdade estaria em ser "um gênero que tem a conversa por modelo"3.

É neste sentido estrito que a liberdade estaria situada na reflexão despreocupada em trazer conclusões, do que decorre a característica da variedade. Esta por sua vez está no fluxo discursivo em oposição ao espírito monotemático no sentido de "lucubrações detidas e extenuantes sobre um assunto só" ${ }^{4}$, todavia não significando dispersão.

\footnotetext{
* Professora Adjunta na Universidade Federal da Paraíba, Centro de Ciências Jurídicas. Líder do GP/CNPq: Realismo Jurídico.

** Professor Associado na Universidade Federal da Paraíba, Centro de Ciências Jurídicas. Líder dos GP/CNPq: "Marxismo e direito", "Filosofia do Direito".

Problemata: R. Intern. Fil. v. 8. n. 3 (2017), p. 160-171 ISSN 2236-8612

doi:http://dx.doi.org/10.7443/problemata.v8i3.37471
} 
E sobre tal unidade, Hume diz que:

Even in our wildest daydreams and night dreams we shall find, if we think about it, that the imagination doesn't entirely run wild, and that even in imagination the different ideas follow one another in a somewhat regular fashion. If the loosest and freest conversation were written down, you would be able to see something holding it together through all its twists and turns. Or, if not, the person who broke the thread might tell you that he had been gradually led away from the subject of conversation by some orderly train of thought that had been quietly going on in his mind. ${ }^{5}$

Com esse argumento Hume tenta elidir a obscuridade e difícil compreensão de que sua obra principal foi alvo. Ao redigir um resumo para $O$ Tratado da Natureza Humana, e assim expressa sua preocupação com o estilo de escrita, que norteia a perspectiva da arte do ensaio:

Readers will more readly apprehend a chain of reasoning, that is more single and concise, where the chief propositions only are linkt on to each other, illustrated by some simple examples, and confirmed by a few of the more forcible arguments. ${ }^{6}$

Além de referência para o estilo ensaístico do artigo, Hume é ponto de partida para a reflexão sobre descrição e prescrição, especificamente considerando a falácia naturalista que no Tratado, livro III, Parte I, seçcão II, na qual afirma que em todo sistema moral sempre fica evidente que o autor segue durante algum tempo o modo comum de raciocinar quando de repente em vez das cópulas proposicionais usuais como é e não é, não encontra uma só proposição que não seja deve ou não deve.

Hume reclama a falta de qualquer justificativa ou explicação desta transposição para a nova relação ou afirmação que o deve ou não deve expressa e questiona como tal nova relação pode ser deduzida de outras inteiramente diferentes. ${ }^{7}$

Assim, e pela relevância de tal problemática, é que o objeto aqui proposto se restringe à questão da instransponibilidade entre descrição e prescrição no debate jurídico, que é do que se passa a tratar. 


\section{O criticismo de Hume e a impossibilidade lógica de passagem direta da descrição para a prescrição}

É de se referenciar que, quando se trata de investigação científica há que se distinguirem os fatos de crenças. Seria diferente no direito? Numa carta a Lafargue, em 11/08/1884, Engels caracteriza a sua atitude e a de Marx sobre a questão primeira com a seguinte afirmação: Marx protestaria contra o 'ideal político-social e econômico' que vós Ihes atribuís. Quando se faz ciência não se elaboram 'ideais': elaboram-se resultados científicos. E quando, além de cientista se é um homem de partido, combate-se para levar os ideais que se tem à prática. Quando se parte, pretendendo fazer ciência, de um 'ideal', não se a faz porque não se constrói ciência com posições a priori. ${ }^{8}$

Ora, não se trata - para Engels - de uma separação mecânica e absoluta e sim de um esforço metodológico visto que ele tinha conhecimento pleno que a confusão entre uma esfera e outra já fora examinada pelo nosso autor-objeto, Hume, no já mencionado no tópico anterior, "Tratado da natureza humana".

Assim, trata-se, aqui, de compreender que - no que concerne à teoria e a filosofia do (e sobre o) direito - a tensão entre descrever (ontologicamente) o fenômeno jurídico ou prescrever (axiologicamente) como ele deveria ser expressa uma enorme confusão teórica entre instâncias claramente distintas.

Tal confusão está presente, por exemplo, naquela concepção apologista do direito natural que se expressa na "Antígona" de Sófocles $^{9}$ que retrata o direito a partir de valores transcendentes, imutáveis e universais, tal como identificar o direito com a realização da justiça. ${ }^{10}$

Kelsen, em sua Teoria do direito, lembra que "ninguém pode negar que a afirmação pela qual algo é - isto é, o enunciado com o qual se descreve um fato real - seja essencialmente diferente daquele outro enunciado que afirma que algo deve acontecer, isto é, do enunciado com o qual se descreve uma norma e que, em consequência, de algo que existe não pode deduzir-se que algo deva existir ou do mesmo modo, de que algo deva ser não pode seguir que algo seja". ${ }^{11}$

$\mathrm{Ou}$, nos termos postos, clara e diretamente, por Austin, a existência do direito é uma coisa, seu mérito ou demérito é outra, completamente diferente ${ }^{12}$. $E$ tais pontos de vista nada tem a ver e não implicam, nenhum deles, em tratar a neutralidade do direito não como aspecto formal-processual, mas como uma característica essencial. Ou seja, não reconhecer essa separação ontognosiológica e negar - ou se recusar a ver, o que dá no mesmo - que a forma jurídica é contextualmente estabelecida para definição e manutenção de certos 
interesses e que, assim sendo, é expressão de poder para manter o próprio poder, só contribui para ilusões quanto a supostas virtudes emancipatórias do direito.

Daí tratar o direito no plano prescritivo sob a rubrica de o está descrevendo é incorrer na falácia naturalista que Hume critica. ${ }^{13}$

Por isso, pensar o status da forma jurídica descritivamente através de prédicas como ele deveria ser (isto é, de forma até pré-Kelseniana, na medida em que, para esse autor, o dever-ser tem sentido absolutamente diverso) não significa, para nem para os marxistas, nem para os positivistas e nem para quem tenha o mínimo de mentalidade científica, prestar-se reverência aos fatos sociais como fatos brutos.

O marxismo não é uma variante de um mero praticismo e nem os positivistas jurídicos podem ser confundidos com positivistas filosóficos. Os primeiros veem a própria prática social enquanto práxis reflexiva e não toscamente reiterativa, o que a confundiria com uma forma de poiesis ${ }^{14}$. Os segundos por sua vez, por limites ideológicos e lugar de classe têm como horizonte a estabilização do status quo e das relações jurídicas, mas causam menos mal à teoria e a filosofia do direito do que as crenças jusnaturalistas.

Assim, a inversão entre o que o direito representa em sua exterioridade (aparência) e a sua essência levam as confusões dignas de atenção e de superação dado que tal problemática não é supérflua visto que a convergência entre aparência e essência tornaria a ciência, enquanto atividade explicativa / compreensiva do mundo, desprovida de qualquer pape ${ }^{15}{ }^{16}$. $\mathrm{E}$, nesse tocante da práxis jurídica, uma corrente filosófica que não se pode atribuir a pecha de marxista, caracterizada por certa vocação empirista, acaba dando uma contribuição para a reflexão sobre a atividade de decisão judicial, pelo que aporta às assim chamadas 'razões do direito. Nos referimos especificamente ao pragmatismo jurídico - uma variante do pragmatismo americano.

\section{A concepção pragmática de efeitos práticos como uma categoria útil para a compreensão do direito e o processo da ratio decidendi}

Para dar conta, numa segunda etapa, da crítica aos que querem forçadamente conectar o que é e o que deve ser, far-se-á, nesta secção, uso do pragmatismo e de suas relações com o direito a partir da perspectiva teórica formulada pelo teórico do realismo jurídico americano, Benjamin Nathan Cardozo, em $A$ natureza do processo judicial. Para tanto nos valeremos aqui, a título de 
paradigma, do conceito de abdução em Peirce.

A intensa influência destes e de outros pensadores não poderia ser desconsiderada se temos como objetivo trabalhar a concepção pragmática de efeitos práticos como uma categoria útil para a compreensão das normas jurídicas e da distinção entre ser e dever-ser.

Após esta análise prospectiva procuraremos dar conta de uma das vicissitudes do pragmatismo frente a um dos problemas chaves do direito e da teoria do conhecimento: a interpretação dos fatos e como neles se faz uso jurídico da abdução que, no caso, não atropela com contorcionismos hermenêuticos a intransponibilidade de que trata Hume.

E é exatamente na discussão da interpretação dos fatos, sob ótica da teoria e da filosofia do direito, que o ensaio, a essa altura, pretende expor e investigar como a interpretação judicial desenvolvida na construção da sentença ou na natureza do processo judicial, nas palavras de Cardozo, expressa o raciocínio abdutivo de Peirce por introduzir ideias novas acerca do processo decisório enquanto manifestação do resultado de uma previsão normativa resultante do fato e que não põe em dúvida e nem em crise a mencionada separação ontológica aqui tratada.

Partindo do pressuposto que as ideias do realismo jurídico são um desenvolvimento da filosofia pragmática aplicadas ao direito ${ }^{17}$, apesar da teoria tradicional desconhecer este raciocínio abdutivo e apenas conceber a dedução como operação lógica de subsunção da norma ao caso e insistir em que o deverser da norma derivaria de um suposto ser da mesma.

Assim, analisar a lógica da decisão judicial é perceber dois principais momentos: o contexto da descoberta e o da justificação ${ }^{18}$. Este segundo é o exercício formal da dedução, pois a ratio decidendi parte de uma premissa geral (a norma) até a premissa particular (o caso), assim, a conclusão é um silogismo apresentado na sentença.

Entretanto, a interpretação se desenvolve mesclada com elementos subconscientes - nas ideias de Cardozo - e se realiza no contexto da descoberta, momento em que se estudam fatos e se cria uma teoria para explicá-los, muitas vezes, especialmente nos hard cases, de forma abdutiva e sem nenhuma preocupação - vã - de tentar extrair o ought de um suposto ser da norma, quando não dos próprios fatos.

A forma de apresentação da decisão toma a estrutura de dedução apenas e tão somente enquanto raciocínio de justificação a posteriori para cumprir requisito dogmático fundamental da inegabilidade dos pontos de partida. 
Ora, a teoria tradicional do direito (presa à ilusão que do ser pode se extrair um dever) ensina que a decisão judicial é um silogismo lógico, pois temos uma premissa maior, a menor e a conclusão. A apresentação da tomada de decisão como um silogismo, toma a forma pelo conteúdo e assim o dever ser pelo ser, pelo que incorre na falácia humeana.

Se apresentarmos a estrutura lógica da norma podemos ver os seus componentes.

Observe estes exemplos:

1) Todos os homens são mortais (premissa maior)

Sócrates é humano (premissa menor)

Logo, Sócrates é mortal (conclusão)

2) Artigo 121, Código Penal: Matar alguém.

Pena: reclusão, 6 (seis) a 20 (vinte anos.

Peter mata Bill.

Peter é condenado a $x$ anos de prisão.

\} Premissa maior

(caso concreto $=$ premissa menor)

(decisão = conclusão)

Quando se analisa estes exemplos, é possível perceber que a estrutura formal é a mesma, porém a principal questão é observar que na segunda situação temos um meio de expressar o raciocínio dedutivo. Entretanto, a ratio decidendi não é exatamente um silogismo

Se perguntarmos o porquê, para responder esta questão temos que analisar dois pontos:

a) $\mathrm{O}$ que significa a ratio decidendi ?

b) $\mathrm{O}$ que são e quais são as diferenças entre contexto de descoberta e contexto de justificação?

A ratio decidendi é uma expressão jurídica que refere-se ao princípio ou ponto os quais determinam o julgamento. Quando pensamos acerca dos elementos usados pela Corte para compor uma decisão particular, de acordo com Benjamin Nathan Cardozo,

Alguns princípios, ainda que não ditos, inarticulados e subconscientes, têm regulado esta "infusão" ${ }^{19}$. Pode não ter sido o mesmo princípio para todos os juízes em todos os tempos. Porém, a escolha tem sido não a submissão ao decreto do fato; as considerações e motivos que determinam a escolha ficam freqüentemente obscuros, ao largo das análises. ${ }^{20}$

Com tal ideia de Cardozo, a dedução lógica como meio para explicar a 
decisão resta criticada. O ponto de partido não é a norma, porém alguns elementos subconscientes, nas palavras do autor. ${ }^{21}$

Pode-se, aqui, também se levar em conta, e debater, a da influência das ideias de William James ${ }^{22}$ no pensamento de Cardozo, pelo que é possível dizer que estes elementos subconscientes simbolizam a variedade de tipos de temperamentos intelectuais.

Diz James:

Os temperamentos não são reconhecidos pela razão [...] surge assim uma certa insinceridade em nossas discussões filosóficas: o principal de todas as nossas premissas nunca é mencionado. [...] nossos temperamentos intelectuais são uma mistura de opostos ingredientes, cada um presente em variadas proporções. $^{23}$

Ora, a atividade judicial não é isolada, o juiz é um ser humano e tem sentimentos, concepções, pré-compreensões entre outros, denominadas de elementos subconscientes por Cardozo. E quando se promove um diálogo entre Cardozo e Peirce, a ideia de consequências práticas é uma opção para se entender o processo de decisão.

Para entender a expressão consequências práticas que aparece na definição peirceana de pragmatismo ${ }^{24}{ }^{25}$ e sua relevância para o raciocínio jurídico, o primeiro passo é refletir sobre o significado do raciocínio abdutivo na medida em que ele consiste em estudar fatos e, rigorosamente, inventar (inventio) uma teoria para explicá-los, sendo, pois, a única operação lógica que introduz ideias novas.

Daí é que todas as ideias (hipóteses explicativas) da ciência vêm através da abdução, dispensando inteiramente contorcionismos filosóficos devidamente refutados por uma tradição filosoficamente estabelecida que vem de Hume até Kelsen.

\section{Considerações finais: contexto de descoberta e contexto de justificação da decisão judicial enquanto expressões de atividade descritiva no direito}

A decisão é uma expressão formal de um raciocínio dedutivo, porém nossa tese é que na natureza do processo judicial está um raciocínio abdutivo, logo, abdução legal, se assim se puder chamar. 
Para ser mais preciso, imagine uma situação em que um caso " $X$ " apresenta as características C1, C2, C3, e o conceito jurídico "N" corresponde a tais características existentes; o caso $X$ será classificado como uma instância daquele conceito. Esta classificação não é dedução, porém abdução, pois temos uma hipótese no sentido lógico dado por Peirce para este termo, o qual significa uma inferência classificatória ao substituir a premissa mais geral por outros predicados menos gerais. $^{26}$

De acordo com Tuzzi, dois tipos de abdução legal podem ser distinguidas: uma explanatória ao objetivar a reconstrução dos fatos relevantes e uma classificatória ao objetivar a conceituação legal daqueles fatos. Se nós observarmos o processo de pensamento, primeiro nos sugerimos uma hipótese, uma idéia possível, um tipo de insight, porque é apenas provável; depois determinamos as conseqüências concebíveis das hipóteses, para então expor os resultados.

Ainda, conforme Tuzzi, nos tipos de abdução - explanatória e na classificatória:

(i) o sentido explanatório é a inferência que vai dos efeitos para a causa, a partir dos fatos conhecidos para o desconhecido, criando uma hipótese sobre o que aconteceu.

(ii) O sentido classificatório é a inferência que classifica alguns fatos reais ao abrigo de um tipo de fato, ela parte das características dos contabilizados (i) para a regra, ou melhor, a abdução classificatória encontra a regra ou o princípio que articula esse tipo de fato e suas conseqüências normativas.

A abdução jurídica, em sentido lato, é a combinação de abdução (i) e (ii).

Porém, os teóricos do direito trabalham a decisão como um meio da premissa maior para a premissa menor. No entanto, os juízes decidir e, depois, eles buscam normas para justificar suas decisões.

Podemos identificar dois momentos na decisão: contexto da descoberta e da justificação. Estas expressões foram usadas em 1938 por Hans Reichenbach, um epistemólogo alemão, mas a distinção entre os termos é mais antiga, em 1830, Johannes Herschel escreveu como se obter conhecimento e como produzir induções. $^{27}$

A primeira é o contexto da descoberta, onde temos os fatores psicológicos que levam alguém a uma decisão. A segunda simboliza as razões que foram apresentadas.

Em primeiro lugar, temos decisões, eles são criados por uma variedade de 
infinitas razões que não podemos saber quais são; eles promovem e contribuem para um momento criativo que se revela no raciocínio abdutivo. $O$ segundo momento é formalmente uma maneira de mostrar a decisão, a justificação, aqui se apresentam as bases normativas que fundamentaram a decisão, conforme a lei, ou melhor, de acordo com a principal condição dogmática que é a inegabilidade dos pontos de partida, os quais são as normas.

Explicar tais razões é argumentação. Argumentar é apresentar a estrutura lógica que proporciona as conclusões, e as conclusões aparecem como raciocínio dedutivo que é o caminho formal de se mostrar o raciocínio abdutivo.

\section{REFERÊNCIAS}

CARDOZO, Benjamin Nathan. The nature of judicial process. New York: Dover, 2005.

ESSAY. Essential english dictionary. Chambers harrap publishers: 1999.

ENGELS, Friedrich. Correspondence Engels - Lafargue. Paris: Éditions Sociales, 1975.

FEITOSA; FREITAS. Para uma crítica ao moralismo jurídico sob a perspectiva da filosofia da práxis: A forma jurídica, entre descrição e prescrição. VIII Colóquio Internacional Marx e Engels - CEMARX/UNICAMP, GT 3 Marxismo e Ciências Humanas. 2015. Disponível em

<https://www.ifch.unicamp.br/formulario_cemarx/selecao/2015/trabalhos2015/enoq ue $\% 20$ feitosa $\% 20$ e $\% 20$ lorena $\% 20$ freitas $\% 2010582$.pdf>.

FREITAS, Lorena; FEITOSA, Enoque. As ilusões referenciais do juspositivismo e do jusnaturalismo a partir de uma leitura marxista-realista da "Antígona" de Sófocles. In: RUBIO, David Sánchez; OLIVEIRA, Liziane; COELHO, Carla. Teorias críticas e direitos humanos: Contra o sofrimento e a injustiça social. CRV: Curitiba, 2016.

- Realismo jurídico como pragmatismo: Acerca da tese realista de que direito é o que os juízes dizem que é direito. João Pessoa: Ed UFPB, 2016. 
HUME, David. Enquiry Concerning Human Understanding. Jonathan Bennett, 2017, p. 10, disponível em

<http://www.earlymoderntexts.com/assets/pdfs/hume1748.pdf>.

. An abstract of a book lately published, entituled, A Treatise of Human Nature. Gale ECCO, Print Editions, UK: 2010.

- Tratado da natureza humana: Uma tentativa de introduzir o método experimental de raciocínio nos assuntos morais. São Paulo: Unesp, 2001.

IBRI, Ivo Assad. As conseqüências de conseqüências práticas no pragmatismo de Peirce. In: Cognitio. Centro de Estudos do Pragmatismo - Dept. Filosofia PUC-SP. N. 1. Nov. São Paulo: EDUC; Palas Athena, 2000.

. Kósmos noētós: arquitetura metafísica de Charles S. Peirce. São Paulo: Perspectiva, 1992.

JAMES, William. Pragmatism. New York: Dover, 1995.

KELSEN, Hans. Teoría Pura del Derecho. Mexico: UNAM, 1991.

MARX, Karl. O Capital. São Paulo: Abril Cultural, 1983.

MOORE, G.E. Principia Ethica. Lisboa: Calouste Gulbekian, 1993.

PEIRCE, Charles Sanders. How to make our ideas clear. In: Popular Science Monthly. (January 1878). < http://www. peirce.org/writings/p119.html>.

PESSOA JR., Osvaldo. Contexto de descoberta e de justificação. In: Filosofia da física clássica. São Paulo: USP, 2007.

SOFOCLES. Antígona. Porto Alegre: L\&PM, 2006.

SMITH, Adam. Conferências sobre retórica e belas-letras. Topbooks: Rio de Janeiro, 2008.

SUZUKI, Márcio. O ensaio e a arte de conversar. Pósfácio. In: HUME, David. A 
arte de escrever ensaio. São Paulo: lluminuras, 2011.

\title{
TUZZI, Giovanni. Legal abductions. Disponível em <http://www.jurix.nl/pdf/j03- 05.pdf>. Acesso em 20 ago 2008.
}

\author{
WRÓBLEVSKY, Jerzy. Constitución y teoria general de la interpretacción jurídica. \\ Madrid: Civitas, 1985
}

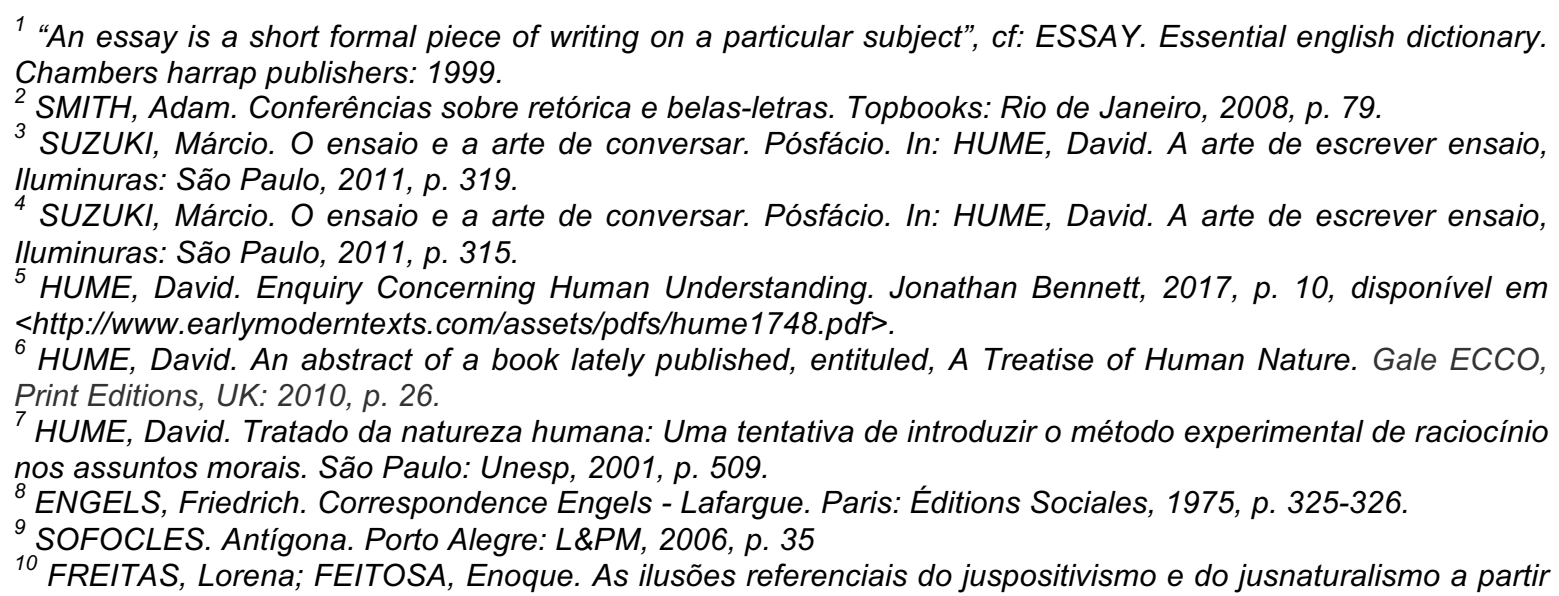
de uma leitura marxista-realista da "Antígona" de Sófocles. In: RUBIO, David Sánchez; OLIVEIRA, Liziane; COELHO, Carla. Teorias críticas e direitos humanos: Contra o sofrimento e a injustiça social. CRV: Curitiba, 2016, p. 365.

11 KELSEN, Hans. Teoría Pura del Derecho. Mexico: UNAM, 1991, p. 19.

12 AUSTIN. The province of jurisprudence determined. London: Library of ideas, 1954, p. 184-185. Lteralmente: the existence of law is one thing; its merit or demerit is another; Wheter it be or be no is one enquiry; whether it or not be conformable to na assumed standard, is a diferente enquiry.

${ }^{13}$ No mesmo sentido MOORE, G.E. Principia Ethica. Lisboa: Calouste Gulbekian, 1993, especialmente a secção 24, capítulo II, que trata do naturalismo ético.

${ }^{14}$ FEITOSA; FREITAS. Para uma crítica ao moralismo jurídico sob a perspectiva da filosofia da práxis: $A$ forma jurídica, entre descrição e prescrição. VIII Colóquio Internacional Marx e Engels - CEMARX/UNICAMP, GT 3 Marxismo e Ciências Humanas. 2015, p.2 . Disponível em <https://www.ifch.unicamp.br/formulario_cemarx/selecao/2015/trabalhos2015/enoque\%20feitosa\%20e\%20lore na\%20freitas\%2010582.pdf>.

${ }^{15}$ MARX, Karl. O Capital. São Paulo: Abril Cultural, 1983, tomo 2, p. 271.

16 FEITOSA; FREITAS. Para uma crítica ao moralismo jurídico sob a perspectiva da filosofia da práxis: $A$ forma jurídica, entre descrição e prescrição. VIII Colóquio Internacional Marx e Engels - CEMARX/UNICAMP, GT 3 Marxismo e Ciências Humanas. 2015, p. 5. Disponível em <https://www.ifch.unicamp.br/formulario_cemarx/selecao/2015/trabalhos2015/enoque\%20feitosa\%20e\%20lore na\%20freitas\%2010582.pdf>. 
${ }^{17}$ FREITAS, Lorena. Realismo jurídico como pragmatismo: Acerca da tese realista de que direito é o que os juízes dizem que é direito. João Pessoa: Ed UFPB, 2016, cap. 1.

${ }^{18}$ WRÓBLEVSKY, Jerzy. Constitución y teoria general de la interpretacción jurídica. Madrid: Civitas, 1985, p. 97. WRÓBLEVSKY, Jerzy. Constitución y teoria general de la interpretacción jurídica. Madrid: Civitas, 1985. É em nome dessa distinção entre contexto de descoberta e de justificação, metodologicamente mais relevante para compreender a argumentação judicial que, o autor mencionado abandona a teorização de justificação interna e interna.

${ }^{19}$ Cardozo describes the judicial decision as a strange compound which is brewed daily in the caldron of the courts. CARDOZO, Benjamin Nathan. The nature of judicial process. New York: Dover, 2005, p. 6.

${ }^{20}$ Idem, p. 7.

21 Idem, p. 163.

22 Esta tese foi debatida no 10o Encontro Internacional de Pragmatismo: Acerca da vocação pragmática do realismo jurídico Americano a partir das idéias de Benjamin Cardozo sobre a natureza do direito.

<http://www.pucsp.br/pos/filosofia/Pragmatismo/eventos/10enc_prag/10_enc_ingl_com_abstracts.htm>.

23 JAMES, William. Pragmatism. New York: Dover, 1995, p. 2, $\overline{3}$.

${ }^{24}$ PEIRCE, Charles Sanders. How to make our ideas clear. In: Popular Science Monthly. (January 1878). $<$ http://www.peirce.org/writings/p119.html>.

${ }^{25}$ Entretanto, é necessário lembrar, de acordo com Ibri, que a expressao aparece novamente quando Peirce tenta explicar o que significa a verdade, em artigo escrito em 1905. IBRI, Ivo Assad. As conseqüências de conseqüências práticas no pragmatismo de Peirce. In: Cognitio. Centro de Estudos do Pragmatismo - Dept. Filosofia PUC-SP. N. 1. Nov. São Paulo: EDUC; Palas Athena, 2000, p. 30-31; IBRI, Ivo Assad. Kósmos noētós: arquitetura metafísica de Charles S. Peirce. São Paulo: Perspectiva, 1992, p. XV, 19ss.

${ }^{26}$ TUZZI, Giovanni. Legal abductions. Disponível em <http://www.jurix.nl/pdf/j03-05.pdf>. Acesso em 20 ago 2008.

${ }^{27}$ PESSOA JR., Osvaldo. Contexto de descoberta e de justificação. In: Filosofia da física clássica. São Paulo: USP, 2007, p. 40. 